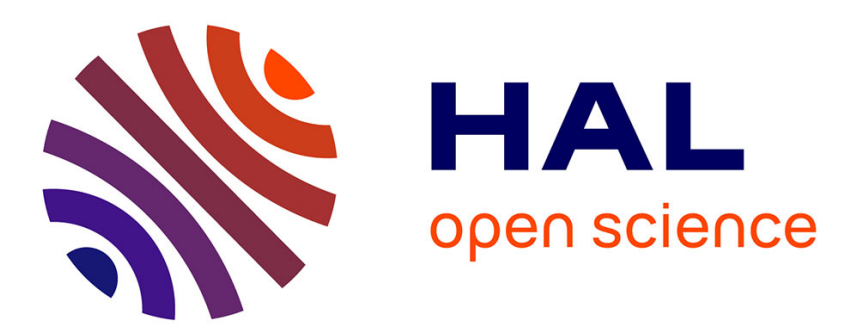

\title{
On the Evaluation of Stress Triaxiality Fields in a Notched Titanium Alloy Sample via Integrated DIC
}

Dominik Lindner, Florent Mathieu, François Hild, Olivier Allix, Cuong Ha Minh, Olivier Paulien-Camy

\section{- To cite this version:}

Dominik Lindner, Florent Mathieu, François Hild, Olivier Allix, Cuong Ha Minh, et al.. On the Evaluation of Stress Triaxiality Fields in a Notched Titanium Alloy Sample via Integrated DIC. Journal of Applied Mechanics, 2015, 82 (7), pp.4030457. 10.1115/1.4030457 . hal-01166848

\author{
HAL Id: hal-01166848 \\ https://hal.science/hal-01166848
}

Submitted on 23 Jun 2015

HAL is a multi-disciplinary open access archive for the deposit and dissemination of scientific research documents, whether they are published or not. The documents may come from teaching and research institutions in France or abroad, or from public or private research centers.
L'archive ouverte pluridisciplinaire HAL, est destinée au dépôt et à la diffusion de documents scientifiques de niveau recherche, publiés ou non, émanant des établissements d'enseignement et de recherche français ou étrangers, des laboratoires publics ou privés. 


\title{
On the Evaluation of Stress Triaxiality Fields in a Notched Titanium Alloy Sample via Integrated DIC
}

\author{
Dominik LINDNER, Florent MATHIEU, François HILD, Olivier ALLIX; Cuong HA MINH \\ LMT, ENS Cachan/CNRS/Université Paris Saclay \\ 61 avenue du Président Wilson, F-94235 Cachan Cedex, France \\ Email: allix@Imt.ens-cachan.fr \\ Olivier PAULIEN-CAMY \\ Turbomeca (SAFRAN Group), avenue Joseph Szydlowski, F-64511 Bordes, France \\ Email: olivier.paulien@turbomeca.fr
}

\begin{abstract}
This paper presents a coupled experimental/numerical procedure to evaluate triaxiality fields. Such a type of analysis is applied to a tensile test on a thin notched sample made of Ti 6-4 alloy. The experimental data consist of digital images and corresponding load levels, and a commercial code (Abaqus) is used in an integrated approach to Digital Image Correlation (DIC). With the proposed procedure, samples with complex shapes can be analyzed independently without having to resort to other tests to calibrate the material parameters of a given constitutive law to evaluate triaxilities. The regularization involved in the integrated DIC procedure allows the user to deal with experimental imperfections such as cracking of the paint and/or poor quality of the speckle pattern. For the studied material different hardening postulates are tested up to a level of equivalent plastic strain about three times higher than those achievable in a tensile test on smooth samples. Different Finite Element discretizations and model hypotheses (i.e., 2D plane stress and 3D simulations) are compared.
\end{abstract}

\section{Introduction}

In the design of turbo-engines, it is required to ensure safety margins between the operating conditions and burst. A criterion, which is based upon the calculation of the average hoop stress, was proposed by Robinson [1] and is used to estimate the burst speed of disks. In the case of complex geometries and material models, this criterion is not accurate enough. Today's trend is to try to reduce safety margins by relying on local burst predictions where finite element simulations are performed to take into account precisely both the complex geometry of actual disks and the constitutive model of the material $[2,3]$.

\footnotetext{
*also at Turbomeca

${ }^{\dagger}$ Corresponding author
}

The burst prediction through local approaches strongly depends on the modeling and identification of the constitutive behavior [2,3]. For the studied material, a Hosford yield criterion [4] was found to be more appropriate than the J2flow rule. However, even if the burst predictions were improved in comparison with those based on Robinson's criterion, the remaining discrepancy between experiments and numerical predictions has led the aero-engine manufacturers to look for possible explanations and better predictions. A possible source of discrepancy is that the state of stress in the disks, which is estimated via 3D simulations with von Mises' elastoplastic models identified on uniaxial tensile tests on smooth samples (i.e., with triaxialities of the order of 0.33 ), is characterized by higher levels of stress triaxiality for defect-free configurations (i.e., ranging from 0.5 to 0.8 ).

The influence of the stress triaxiality $[5,6]$ and even Lode parameter $[7,8]$ on the plastic behavior of metal and alloys has been the subject of many studies [9-14]. Moreover the stress triaxiality is a key parameter when dealing with damage and failure [15-19]. In addition to the dependence on triaxiality, the studied titanium alloy exhibits an important tension-compression asymmetry, which requires the use of enhanced plasticity models [20]. For the applications of interest, the triaxiality is always positive, which allowed us to test simpler material models. It was decided to conduct experiments on flat notched specimens giving access to levels of triaxiality consistent with the simulations of defect-free disks and allowing for the use of digital image correlation (DIC) techniques. Such sample geometries induce nonuniform strain fields. In that case the measurements of load-dependent displacement fields and their subsequent exploitation to derive strain fields are needed [21,22]. Different optical techniques can be used to measure displacement fields [23, 24]. Among them, DIC is increasingly employed due to its versatility and applicability to "any" scale of obser- 
vation [25,26]. Most of nowadays DIC codes rely on local registrations (i.e., with subimages [27]). Global approaches provide an alternative, which uses kinematic bases that are made consistent with numerical simulations (e.g., finite element DIC [22, 28, 29]).

Even though very powerful, finite element DIC as any DIC approach suffers from the 'resolution/spatial resolution' curse since it is an inverse problem [30]. In particular, it does not allow FE meshes of arbitrarily small sizes to be used. For the test that is analyzed herein this limitation occurs for minimal element sizes of 60 pixels due to the poor random texture. For such element sizes the mechanical FE solution is not refined enough. To correct for such shortcomings, a further step is to integrate even more closely measurements and simulations. This is achieved by resorting to Integrated DIC (I-DIC) that uses mechanically admissible displacement fields as kinematic bases. Such a type of technique was first applied with closed-form (i.e., elastic) solutions [31,32], and then generalized to numerically generated solutions [33-35]. The FE code is used, non intrusively, as a kinematic basis generator and virtual load cell (via sensitivity fields) and the unknown degrees of freedom become either boundary conditions and material parameters [35].

The present paper shows a combined use of DIC and IDIC to evaluate the in situ stress triaxiality in a thin notched sample made of titanium alloy. With the proposed procedure, each sample can be analyzed independently without having to resort to other tests to calibrate the material parameters of a given constitutive law. Moreover the regularization embedded in the I-DIC procedure allows us to deal with experimental imperfection such as cracking of the paint and poor quality of the speckle pattern. In the first part the choice of the sample geometry and the experimental procedure are described. The principles of DIC and I-DIC are briefly summarized in the second part. This technique gives access to the measured boundary conditions that can be prescribed when performing an identification step either using Finite Element Model Updating [36,37] (FEMU) or I-DIC [35]. The latter is utilized herein with different constitutive laws. The results obtained via DIC and I-DIC are analyzed in the third part. Various configurations are studied, namely, 2D and 3D FE simulations, discretizations and constitutive equations. Last, the triaxiality fields are assessed.

\section{Experimental Setup}

A drawback of uniaxial tensile tests on smooth samples is that the onset of localized strain fields occurs at low strain levels making it ill-suited for constitutive and failure characterization [38]. Furthermore the state of stress at failure may be different from that of in-service structures. In the present study the state of stress is characterized by its vonMises level and corresponding triaxiality.

FE simulations are used to design the sample geometry (Figure 1). They are carried out up to 0.12 cumulated plastic strain levels, which is the macroscopic strain to failure for the chosen material tested in tension on a smooth geometry and measured with an extensometer. The aim is to reach at least the lower bound of the targeted triaxiality range (i.e., $0.50)$.

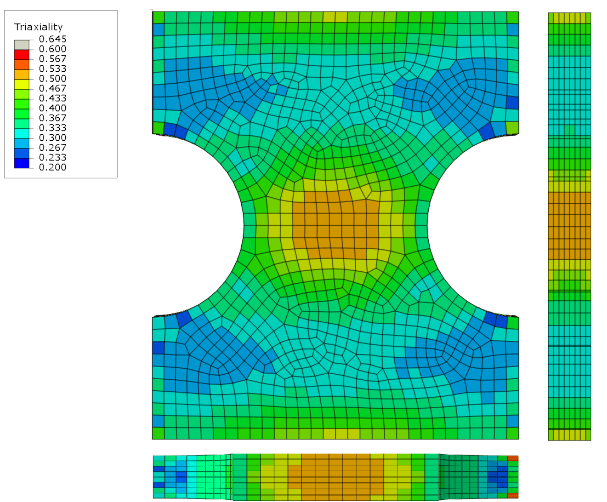

Fig. 1. Triaxiality field obtained by 3D FE elastoplastic simulations on the final sample geometry. Three midsection cuts are shown

The chosen notched sample has a ligament width of $3 \mathrm{~mm}$, a notch radius of $1.5 \mathrm{~mm}$, and a thickness equal to $0.7 \mathrm{~mm}$, see Figure 2). It is made of Ti 6-4 alloy.

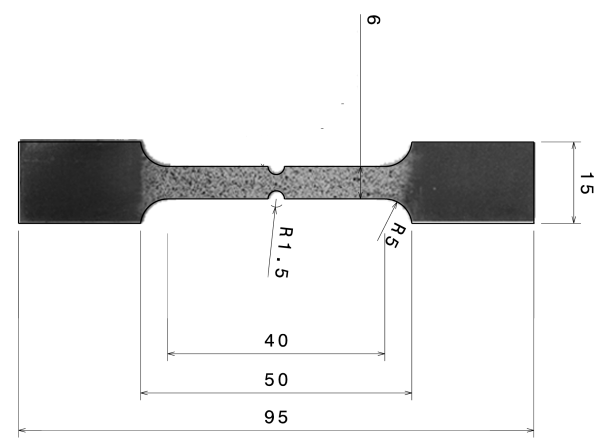

Fig. 2. Sample geometry (nominal dimensions in $\mathrm{mm}$ )

The region in the vicinity of the notches has been monitored with a single camera (definition: $1388 \times 1038$ pixels, 16-bit digitization) and a telecentric lens to minimize the effects associated with out-of-plane motions. With the chosen optical setup, the physical size of one pixel is $6.4 \mu \mathrm{m}$ so that the region of interest (ROI) encompasses the thinned regions (Figure 4). Since the sample surface had to be polished to reach the desired thickness, the texture was more difficult to deposit. Two series of black and white droplets were sprayed and resulted in a rather coarse speckle pattern, which is very challenging for standard DIC approaches. The experiment has been performed in a displacement-controlled mode to allow for softening.

In Figure 3 the influence of the observation scale on the strain response of the specimen is presented. The net section stress corresponds to the applied load $F$ divided by the initial surface $S_{0}$ of the ligament. From the Q4-DIC results 
to be presented in the next section, the macroscopic longitudinal strain corresponds to the mean strain over the whole region of interest. This information would have been available if an extensometer had been used with a gage length $L_{0}=3.97 \mathrm{~mm}$. The corresponding mesoscopic strain corresponds to the average longitudinal strain in an area center about the ligament for a length $L_{0}=0.37 \mathrm{~mm}$. Because of the stress and strain concentrations, the mesoscopic strain level is significantly higher than that at the macroscopic level. In the following, all results will be related to a loading parameter here chosen to be macroscopic strain $\varepsilon_{\text {macro }}$.

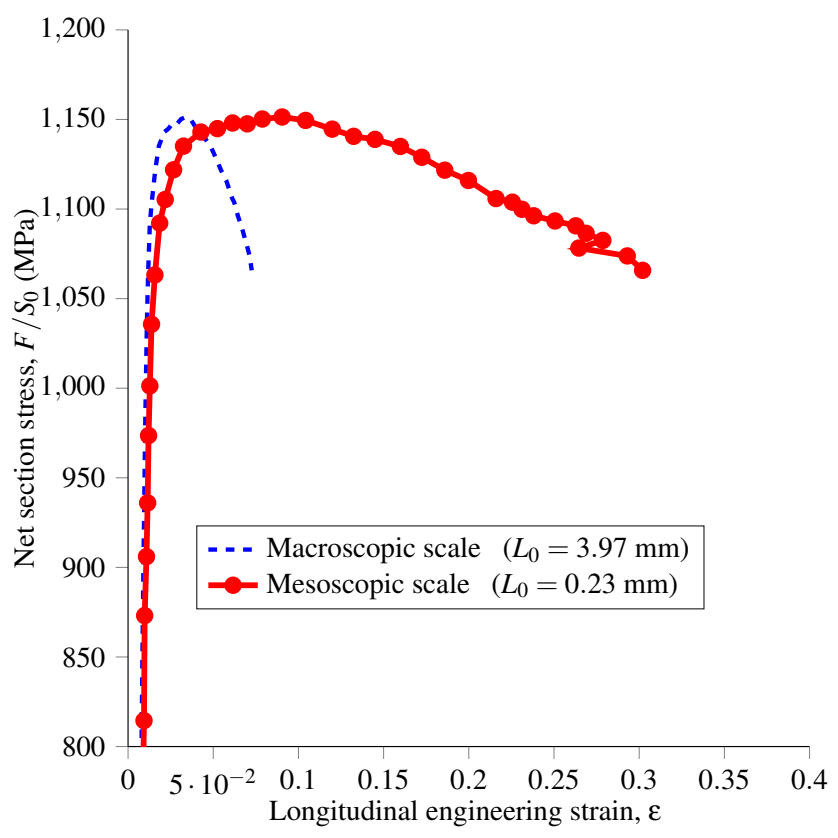

Fig. 3. Longitudinal response of the specimen at macroscopic and mesoscopic scales. Net section stress versus engineering strain for two different gage lengths $L_{0}$

\section{Integrated Digital Image Correlation (I-DIC) \\ 3.1 Principle of I-DIC}

Digital Image Correlation (DIC) consists of measuring displacement fields between a gray level picture $f$ in the reference configuration and a series of pictures $g$ in the deformed configuration [25-27]. The following functional

$$
\eta_{c}^{2}(t)=\frac{1}{|\Omega|} \sum_{\Omega}(g(\mathbf{x}+\mathbf{u}(\mathbf{x}, t), t)-f(\mathbf{x}))^{2}
$$

is to be minimized with respect to the parametrization of the measured displacement field $\mathbf{u}(\mathbf{x}, t)$, where $\mathbf{x}$ is any pixel of the ROI $\Omega$, and $t$ the considered time. Because noise affects both gray level images $f$ and $g$, the previous functional is normalized by $2 \gamma_{f}^{2}$

$$
\chi_{c}^{2}(t)=\frac{\eta_{c}^{2}(t)}{2 \gamma_{f}^{2}}
$$

so that any deviation of correlation residuals from noise induces a level of $\chi_{c}^{2}(t)$ that is on average greater than 1 [35], where $\gamma_{f}^{2}$ is the variance of image acquisition noise that is assumed to be white and Gaussian.

The displacement basis for $\mathbf{u}(\mathbf{x}, t)$ is chosen a priori to minimize $\eta_{c}^{2}$ with respect to the associated amplitudes. Continuous displacement fields found in finite element discretizations are one possible choice [22, 28, 29], which leads to lower uncertainties in the measured displacement fields when compared with local approaches with the same local displacement interpolations [30]. More importantly, such fields can be directly compared with finite element simulations. Most of the applications of finite element DIC reported so far deal with regular meshes made of 4-noded elements. They are considered herein but with unstructured meshes. Such type of DIC approach is referred to as Q4-DIC $[22,30]$.

In the following, Integrated DIC will be used to directly evaluate mechanical fields to extract, say, stress triaxialities. To have access to such fields, the parameters of the chosen constitutive law have to be known. They are part of the proposed procedure, which calibrates them to get the most reliable estimates of triaxialities for the given constitutive model. Let $\{\mathbf{p}\}$ denote the vector gathering all unknown material parameters. The I-DIC setting consists of minimizing globally over space and time the total identification residual with respect to the sought material parameters

$$
\left\{\mathbf{p}^{\text {opt }}\right\}=\underset{\{\mathbf{p}\}}{\operatorname{argmin}} \chi_{\text {tot }}^{2}(\{\mathbf{p}\})
$$

with

$$
\begin{aligned}
\chi_{\mathrm{tot}}^{2} & =\frac{1}{2} \chi_{c}^{2}+\frac{1}{2} \chi_{F}^{2} \\
\chi_{c}^{2} & =\frac{1}{n} \sum_{n} \chi_{c}^{2}(t) \\
\chi_{F}^{2}(\{\mathbf{p}\}) & =\frac{\left(\left\{\mathbf{F}_{\mathbf{m}}\right\}-\left\{\mathbf{F}_{\mathbf{c}}(\{\mathbf{p}\})\right\}\right)^{t}\left(\left\{\mathbf{F}_{\mathbf{m}}\right\}-\left\{\mathbf{F}_{\mathbf{c}}(\{\mathbf{p}\})\right\}\right)}{\gamma_{F}^{2} n}
\end{aligned}
$$

where $\chi_{F}^{2}$ denotes the global equilibrium gap, which is to be minimized in conjunction with the global correlation residuals $\chi_{c}^{2},\left\{\mathbf{F}_{\mathbf{m}}\right\}$ the vector gathering all measured load levels for all considered steps $n,\left\{\mathbf{F}_{\mathbf{c}}\right\}$ the vector gathering all computed load levels, and $\gamma_{F}$ is the standard resolution of the load measurement.

A Newton-Raphson algorithm is implemented to minimize $\chi_{\text {tot }}^{2}$, which is nonlinear with respect to $\{\mathbf{p}\}$. The sensitivities with respect to the sought parameters $\{\mathbf{p}\}$ of the displacement field $\mathbf{u}$ and applied load $F_{c}$ have to be assessed 
iteratively to update the current estimate of the sought parameters

$$
\begin{aligned}
\mathbf{u}\left(\mathbf{x}, t,\left\{\mathbf{p}^{(i)}\right\}\right) & =\mathbf{u}\left(\mathbf{x}, t,\left\{\mathbf{p}^{(i-1)}\right\}\right) \\
& +\frac{\partial \mathbf{u}}{\partial\{\mathbf{p}\}}\left(\mathbf{x}, t,\left\{\mathbf{p}^{(i-1)}\right\}\right)\{\delta \mathbf{p}\} \\
F_{c}\left(t,\left\{\mathbf{p}^{(i)}\right\}\right) & =F_{c}\left(t,\left\{\mathbf{p}^{(i-1)}\right\}\right)+\frac{\partial F_{c}}{\partial\{\mathbf{p}\}}\left(t,\left\{\mathbf{p}^{(i-1)}\right\}\right)\{\delta \mathbf{p}\}
\end{aligned}
$$

where $\left\{\mathbf{p}^{(i-1)}\right\}$ is the set of parameters at iteration $i-1$, and $\{\delta \mathbf{p}\}$ the sought parameter increment. The computation of the sensitivity fields $\partial \mathbf{u} / \partial\{\mathbf{p}\}$ can be performed either analytically $[33,40]$ or numerically by computing the displacement fields for small variations of each parameter of the considered set. In practice, forward finite differences are considered to compute the sensitivity fields with the commercial FE code Abaqus. Similarly, the force sensitivities $\partial F_{c} / \partial\{\mathbf{p}\}$ are evaluated by resorting to finite forward differences. As for FEMU, this type of procedure utilizes any FE code, be it commercial, in a non intrusive way [35].

Both DIC approaches (i.e., Q4-DIC and I-DIC) are to be used in the sequel. Q4-DIC is the reference when the same mesh is used in both approaches since no mechanical hypotheses are made except the continuity of the measured displacement fields. Further, the Dirichlet boundary conditions used in I-DIC analyses are those measured via Q4-DIC so that the comparison of both approaches will be carried out with the same displacements on the loaded boundaries of the ROI. For I-DIC, two different types of mechanical analyses are performed, namely, 2D plane stress simulations and $3 \mathrm{D}$ computations. For the latter ones, the Dirichlet boundary conditions correspond to the extruded measured nodal displacements along the whole thickness of the FE model. Three different meshes are chosen to address numerical convergence. First a so-called coarse mesh (i.e., I-DIC-c) is identical to that used in Q4-DIC (i.e., 60-pixel elements). An intermediate mesh is also constructed and the corresponding I-DIC analysis is labelled I-DIC-i (the typical element size is equal to 25 pixels). Last an even finer mesh is analyzed (i.e., I-DIC-f) with a typical element size of 10 pixels.

FE simulations are performed using reduced integration elements with hourglass stabilization to prevent from volumetric locking. It is worth noting that with the present technique, the mesh can be made as fine as needed since the number of unknowns has been significantly reduced to the number of sought material parameters parameters instead of the nodal degrees of freedom in Q4-DIC. This in turn provides a strong robustness of the whole procedure and allows imperfections such as cracking of the paint and poor quality of the speckle pattern to be dealt with effectively. These challenges are due to the fact that the sample had to be ground to obtain the desired thickness.

\subsection{Constitutive Models}

In I-DIC approaches, one important feature is the choice of the constitutive law. Four different constitutive postulates will be made hereafter:

- linear isotropic elasticity,

- elastoplasticity with J2-flow rule and isotropic hardening described by Ludwik's power law [41]

- elastoplasticity with J2-flow rule and isotropic hardening described by Voce's exponential law [42]

- elastoplasticity with J2-flow rule and isotropic hardening described by extended Voce's law (i.e., exponential + linear hardening).

The identification of Poisson' ratio $v$ turned out to be delicate. The reference value $v=0.32$ was set. In elasticity, only one parameter is sought (i.e., Young's modulus). For Ludwik's law, four parameters are tuned (i.e., Young's modulus, yield stress, hardening modulus and hardening exponent). For Voce's law, four parameters are also determined (i.e., Young's modulus, yield stress, hardening stress and hardening strain). Last, for extended Voce's law, five parameters are calibrated (i.e., Young's modulus, yield stress, hardening stress, hardening strain, and hardening modulus).

\section{DIC and I-DIC Results}

A first series of DIC analyses is run by resorting to Q4DIC in which no mechanical assumptions are made except the fact that the displacement fields are continuous throughout the whole experiment. Figure 4 shows the longitudinal displacement field for the last picture prior to failure (i.e., $\varepsilon_{\text {macro }}=0.072$ ). As expected, there is a very important displacement gradient in the area close to the ligament. The considered mesh is also shown. It corresponds to the lowest element size (i.e., 60 pixels) that can be used to reach convergence of the Q4-DIC code. Such a coarse mesh is due to the poor quality of the random texture. With such conditions, the standard displacement resolution is $0.2 \mu \mathrm{m}$ (or 0.03 pixel) and the corresponding strain resolution is $0.05 \%$. These resolutions were determined by analyzing pictures shot for the reference configuration.

To check the quality of the registration, the dimensionless residual field $\varphi(\mathbf{x}, t)=|g(\mathbf{x}+\mathbf{u}(\mathbf{x}, t), t)-f(\mathbf{x})| / \Delta f$ is shown in Figure 5 for the final measurement, where $\Delta f$ is the dynamic range of the picture in the reference configuration (i.e., $\Delta f=\max _{\Omega} f-\min _{\Omega} f$ ). The mean residual $\varphi_{c}(t)=\langle\varphi(\mathbf{x}, t)\rangle_{\Omega}$ will be shown for each analyzed image in Figure 11. The overall mean residual $\Phi_{c}$ is equal to 0.028 , which indicates that the measured displacements are trustworthy. However, very high residuals are observed in the ligament region. This is an indication that the chosen kinematics associated with the coarse FE mesh is not able to fully capture the actual displacement fluctuations. Strain localization may have occurred in that region. Furthermore one observes paint cracks, represented by large dark spots.

From the measured displacement field, it is possible to estimate strain fields. Having a finite element description of the displacement fields, the displacement gradients are computed by differentiating the shape functions as in any standard mechanical FE code [43]. In the present case the nominal strain component is shown in the longitudinal direction 


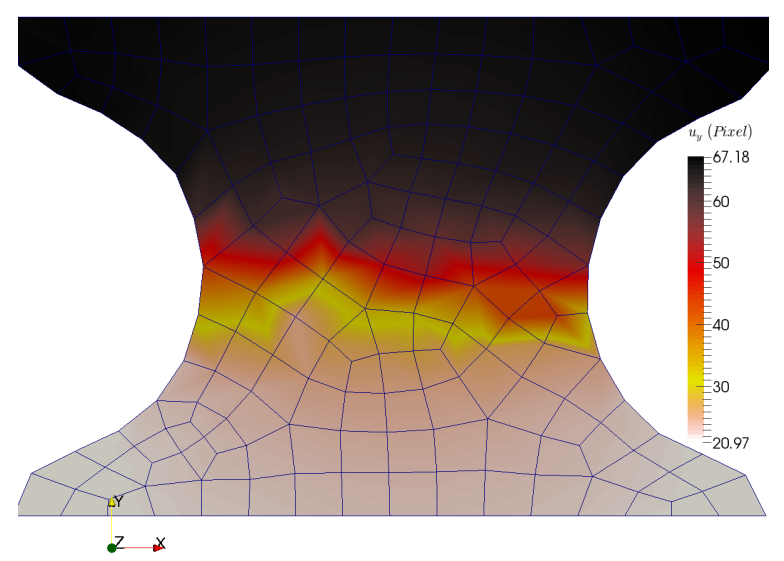

Fig. 4. Longitudinal displacements (expressed in pixels) measured via Q4-DIC when $\varepsilon_{\text {macro }}=0.072$

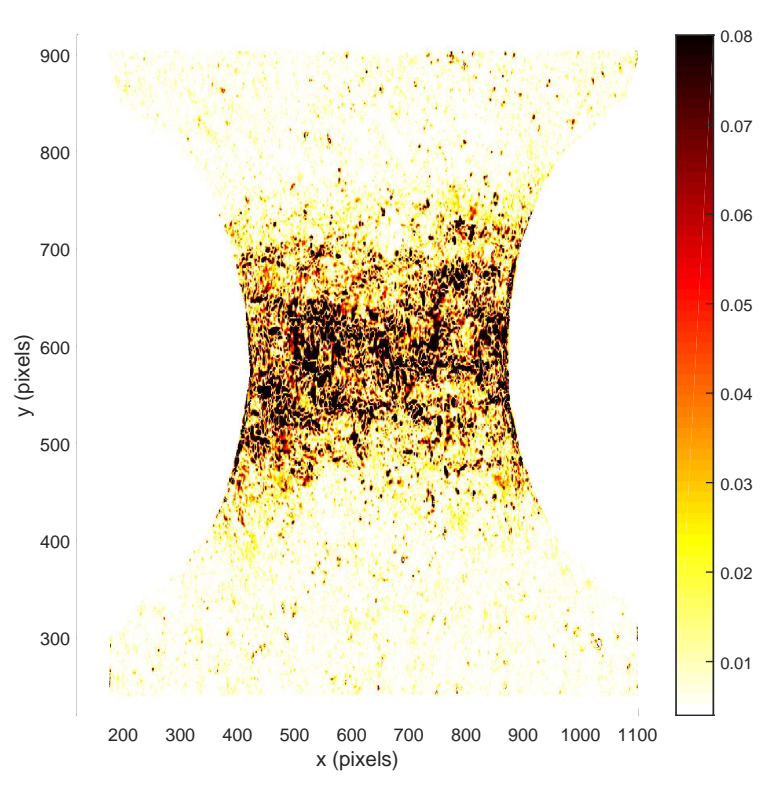

Fig. 5. Normalized gray level residual field $\varphi$ for a Q4-DIC analysis when $\varepsilon_{\text {macro }}=0.072$

\section{in Figure 6.}

The displacements measured via Q4-DIC on the top and bottom edges of the ROI are prescribed as Dirichlet boundary conditions to run I-DIC procedures. In the present case, a 3D mesh and Ludwik's law are considered. The boundary conditions are extruded along the thickness direction. Figure 7 shows the corresponding displacement field measured via I-DIC-3D-f (i.e., 10-pixel elements are considered). Consequently, a smoother field is measured when compared with Q4-DIC. Two reasons explain such results. First, the mesh is finer. Second, I-DIC-3D-f is regularized in a very strong

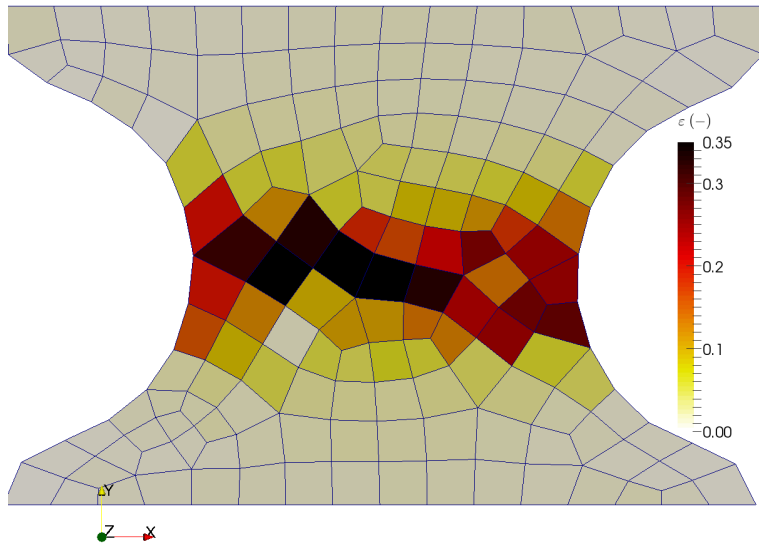

Fig. 6. Longitudinal nominal strain field for a Q4-DIC analysis when $\varepsilon_{\text {macro }}=0.072$

way since the identified field is mechanically admissible in an FE sense.

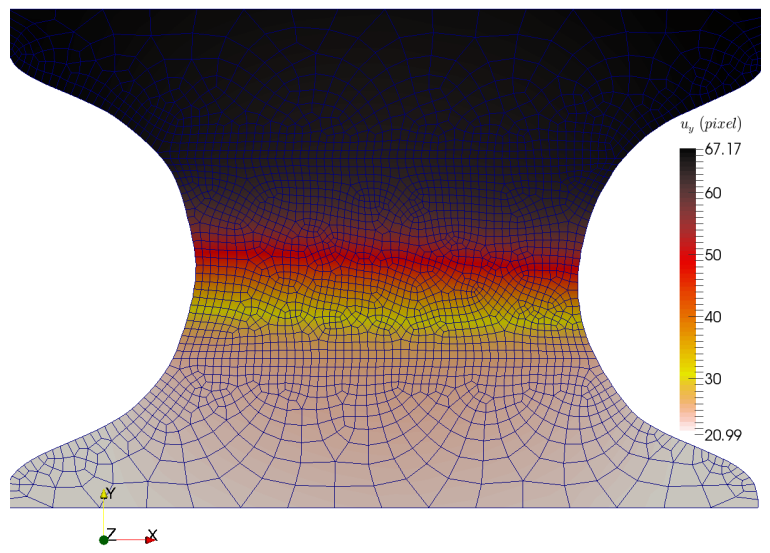

Fig. 7. Longitudinal displacements (expressed in pixel) measured via I-DIC-3D-f when $\varepsilon_{\text {macro }}=0.072$

The quality of the registration is again assessed with the dimensionless residuals for the last analyzed picture (Figure 8). The mean value over all images and the entire ROI is equal to 0.033 , which indicates that the measured displacements are trustworthy, too. This level is slightly higher than that observed with Q4-DIC (i.e., 0.028). This is to be expected when a model error occurs. The latter is mainly located in the ligament region. In the other parts of the sample, the residuals are very low. 


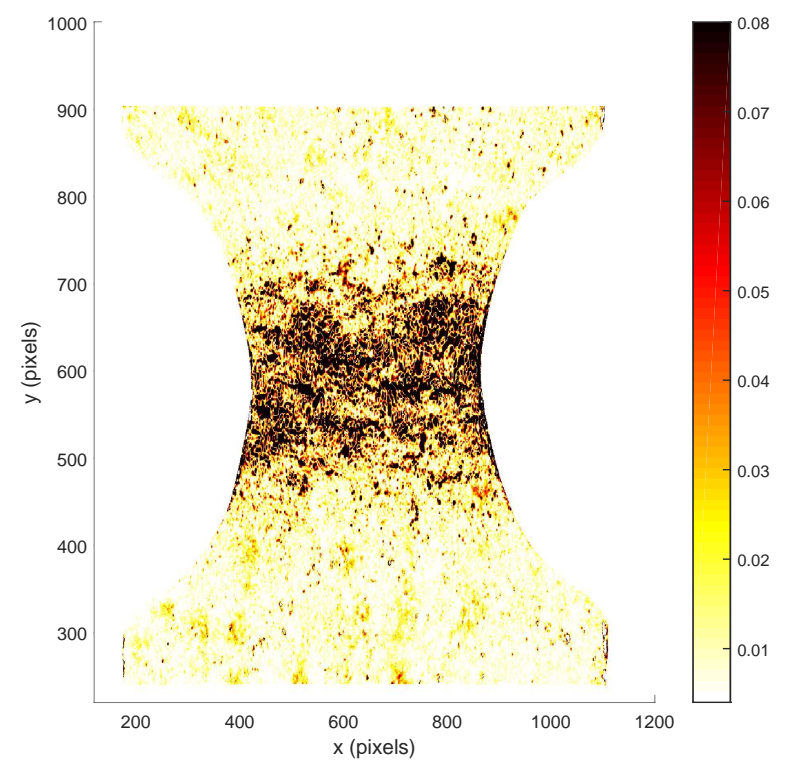

Fig. 8. Normalized gray level residual field $\varphi$ for an I-DIC-3D-f analysis when $\varepsilon_{\text {macro }}=0.072$

Figure 9 shows the longitudinal strain field at the last step of the experiment. Thanks to I-DIC enabling for finer meshes, the spatial distribution of strains is better described in addition to the strain concentrations in the ligament region.

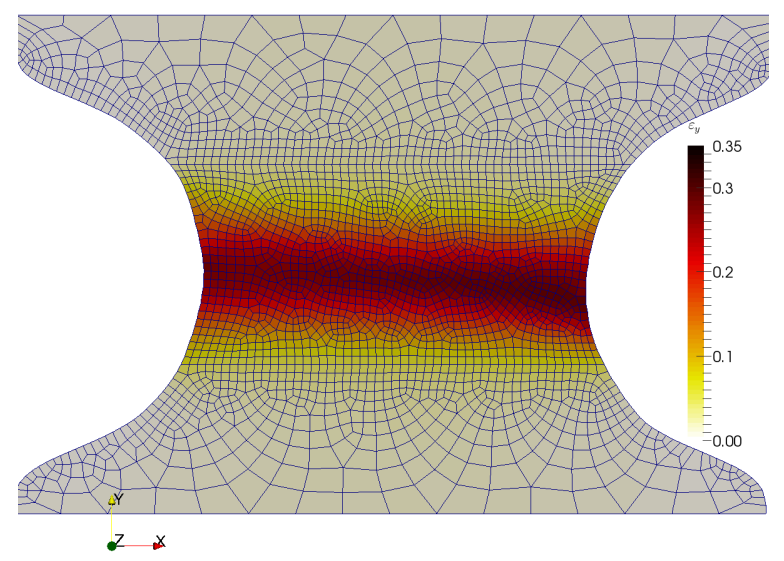

Fig. 9. Longitudinal nominal strain field for an I-DIC-3D-f analysis when $\varepsilon_{\text {macro }}=0.072$

To get a more quantitative comparison, Figure 10 reports the absolute difference of correlation residuals between the two analyses. Except in the central part of the sample, the levels are very small and close to noise contributions. When compared with Figures 5 and 8, the levels in the central part are significantly lower. These results validate both DIC approaches and show that kinematic details near the ligament are captured neither by Q4-DIC nor I-DIC-3D-f for the analyzed picture.

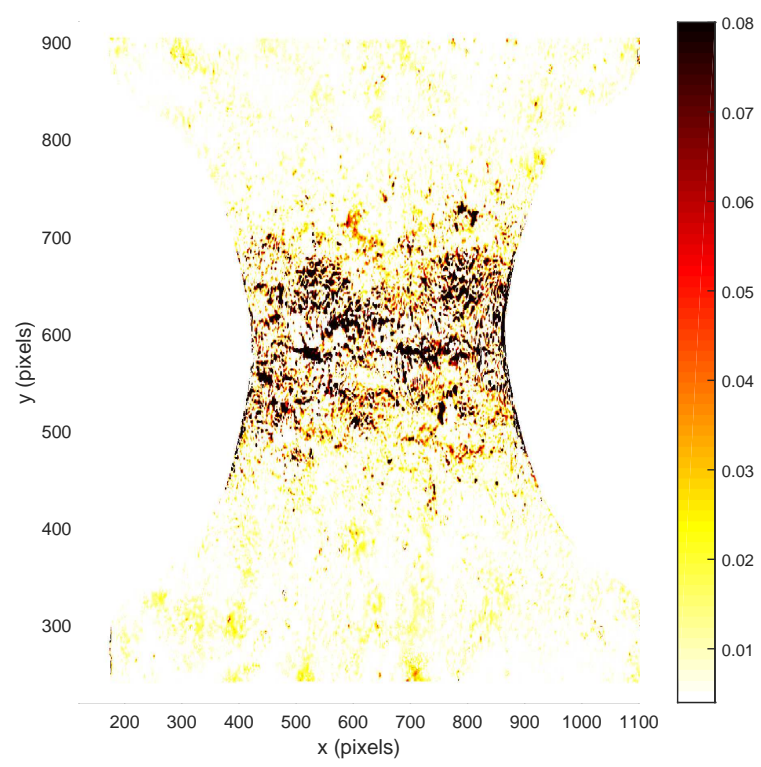

Fig. 10. Absolute difference of normalized gray level residuals between a Q4-DIC and an I-DIC-3D-f analysis when $\varepsilon_{\text {macro }}=0.072$

Figure 11 shows the change of the mean dimensionless correlation residuals $\varphi_{c}$ for the entire analyzed sequence. The two DIC analyses follow a very similar trend. When $\varepsilon_{\text {macro }} \leq 0.02$ the dimensionless residuals are virtually identical for the two DIC approaches and remain close to the acquisition noise. In this part of the experiment, the chosen model is fully validated according to the correlation residuals. When $F \leq F_{\max }$ (i.e., $\varepsilon_{\text {macro }} \leq 0.034$ ) the dimensionless residuals are still close for both DIC approaches. The model is still valid according to the correlation residuals. Conversely, when $F \geq F_{\max }\left(\right.$ i.e., $\varepsilon_{\text {macro }} \geq 0.034$ ) there is a slight divergence of both residuals. The actual displacement fields are no longer precisely captured by the coarse DIC mesh. The quality of the speckle pattern and possibly the cracking of the paint at the late steps of loading play a major role in this increase. However from the small difference between the DIC and I-DIC indicates that the model error remains acceptable in the high strain regime prior to final failure.

Since global equilibrium was also included in the identification residual (see Equation (4)), the measured load level and sum of reaction forces on the edges of the ROI are compared in Figure 12. A very good agreement is observed since the dimensionless root mean square difference is equal to 11 . Most of the difference occurs in the elastic regime. However, since the Young's modulus was one of the parameters to be optimized and its level is consistent with known values it is 


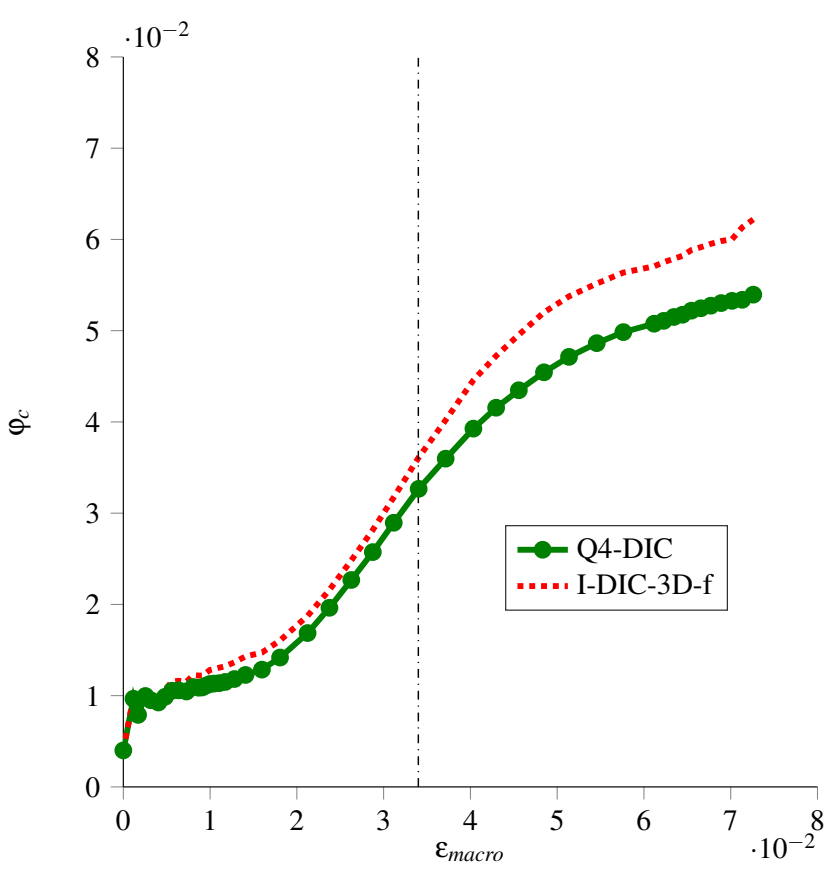

Fig. 11. Mean dimensionless correlation residuals for all the analyze sequence via Q4-DIC (solid line) and I-DIC-3D-f (dashed line)

believed that the discrepancy may be due to experimental imperfections that are not fully captured with 2D-DIC performed on only one face of the sample.

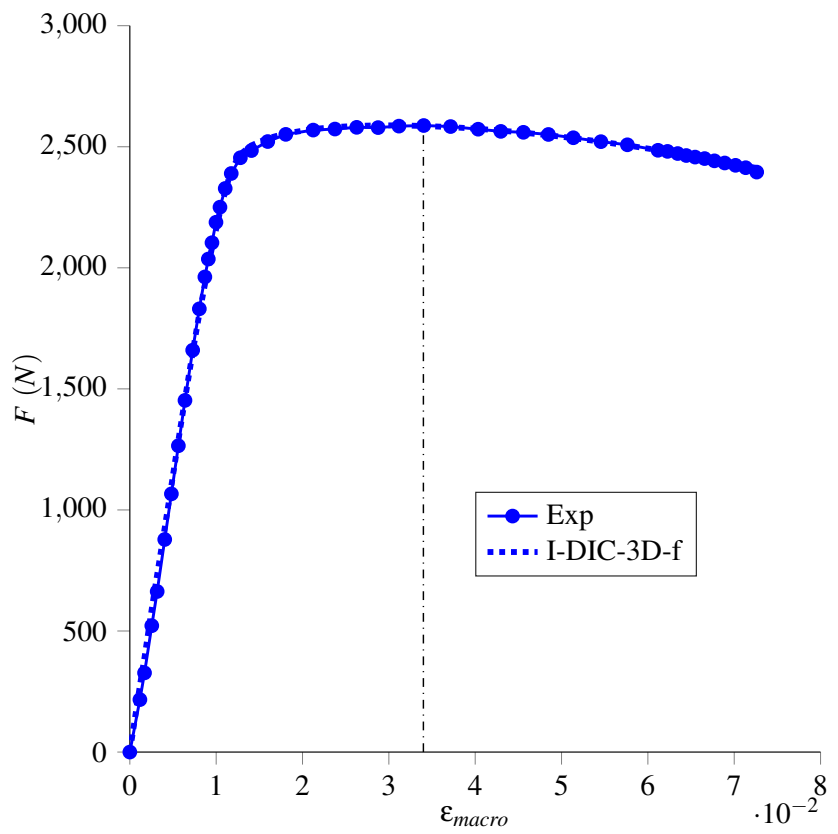

Fig. 12. Comparison between measured and identified (via I-DIC3D-f) load levels. The dash-dotted line corresponds to the maximum load level $\left(F_{\max }\right)$

All the previous residuals are now analyzed in terms of their distance to noise levels in Figure 13. For the whole picture sequence the global identification residual $\chi_{\mathrm{tot}}=9.3$. This level is one order of magnitude greater than that expected if only noise would be detected. A model error is therefore confirmed. In a simpler situation (i.e., strain localization did not occur in a dog-bone sample), levels of the order of 5 have been reported [35]. Consequently, even though a model error is clearly detected, the results should not be discarded.

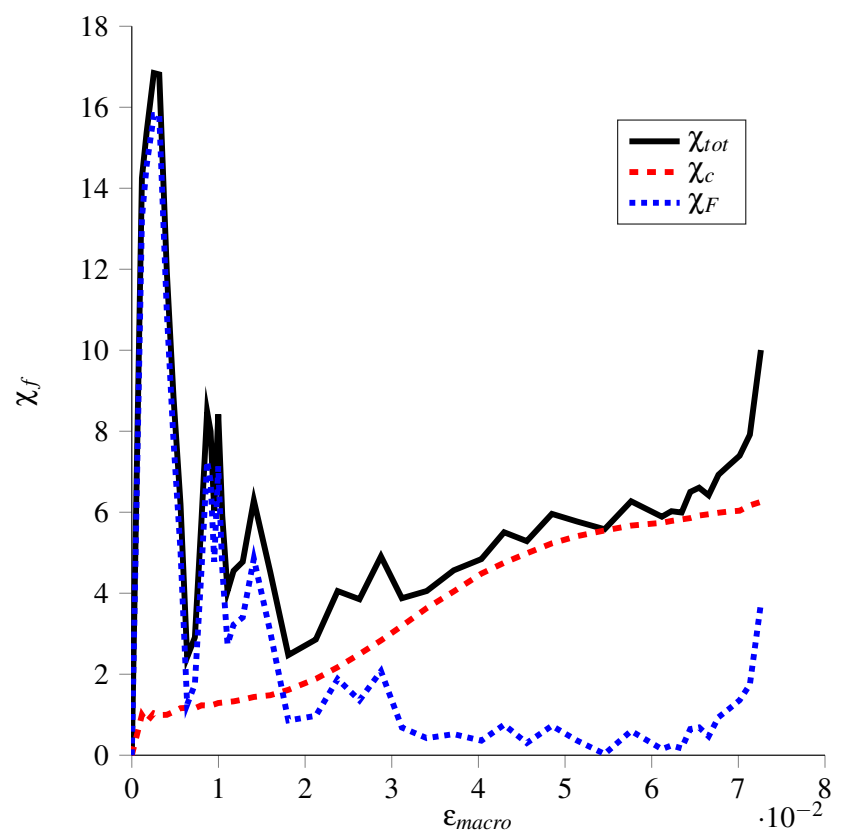

Fig. 13. Identification, correlation and equilibrium residuals with IDIC-3D-f

To analyze the sensitivity of the present results to numerical features (i.e., mesh size, 2D vs. 3D simulations) and model choices, different I-DIC analyses were performed to assess their influence on the global identification residual $\chi_{\text {tot }}$ (Table 1). There is a clear gain when 2D plane stress simulations are compared with 3D simulations, for any type of discretization. Consequently, even though the thickness of the sample is very small (i.e., $0.72 \mathrm{~mm}$ in the present case), a plane stress computation induces a model error that is detected. Concerning the effect of discretization, in the plane stress case the intermediate mesh leads to the lower identification residual. The finest $2 \mathrm{D}$ mesh leads to very high strain levels in the ligament, which are unphysical. Conversely, for the 3D simulations, the two finer discretizations lead to similar identification residuals. With the chosen constitutive model (i.e., Ludwik's law), these two discretizations are equivalent. When compared with Q4-DIC results, the maximum predicted strains are lower. This result can be explained by the fact that the paint has cracked (Figure 5) and that Q4DIC actually accounts for this spurious effect, which is not the case of I-DIC that discards it thanks to the elastoplastic regularization.

The next question is related to the choice of a constitu- 
Table 1. Global identification residual $\chi_{\text {tot }}$ for different analyses and corresponding maximum triaxiality and cumulated plastic strain

\begin{tabular}{|c|c||c||c|c|}
\hline Approach & Constitutive law & $\chi_{\text {tot }}$ & $\eta_{\max }$ & $p_{\max }$ \\
\hline I-DIC-2D-c & Ludwik & 10.7 & 0.57 & 0.39 \\
I-DIC-2D-i & Ludwik & 10.5 & 0.57 & 0.67 \\
I-DIC-2D-f & Ludwik & 11.4 & 0.59 & 0.91 \\
\hline I-DIC-3D-c & Ludwik & 9.7 & 0.7 & 0.28 \\
I-DIC-3D-i & Ludwik & 9.3 & 0.69 & 0.33 \\
I-DIC-3D-f & Ludwik & 9.3 & 0.69 & 0.36 \\
\hline \hline I-DIC-3D-f & Voce & 9.2 & 0.69 & 0.34 \\
I-DIC-3D-f & ext. Voce & 9.1 & 0.68 & 0.34 \\
\hline \hline I-DIC-3D-f & Elastic & 339 & 0.49 & - \\
\hline Q4-DIC & - & - & - & $0.43^{\sharp}$ \\
\hline
\end{tabular}

$\sharp$ indicative value (due to paint cracking)

tive model. To address this issue, the 3D fine mesh is chosen and the model is changed to a standard and extended version of Voce's law. These models induce a second order decrease of the global identification residual $\chi_{\text {tot }}$ (Table 1). Giving more freedom in the hardening response of the material does not induce a significant increase of the identification quality. The model error is not due to a too poor hardening model. Conversely, when an elastic law is assumed during the whole experiment, a very significant degradation of the global identification residual $\chi_{\text {tot }}$ is observed (Table 1 ).

In Figure 14, the equivalent stress/plastic strain responses are shown when described by the three considered hardening models. The latter ones give very similar predictions for equivalent strain levels less than 0.2 . They differ by about $50 \mathrm{MPa}$ at most beyond that strain level. It is interesting to note that the hardening law with the highest number of parameters lies mostly between the two hardening postulates with the lowest degrees of freedom. All these trends confirm that strain localization has occurred at these high equivalent strain levels. For all the chosen models, the same level of static residual is observed. Consequently, all the tested models are fully compatible in terms of applied load and macroscopic strain. Their (small) differences only lie in the displacement fields they induce.

Having no exploitable data with DIC or I-DIC on smooth samples on the same material tested in tension, the present results are compared with very recent data in Figure 15. The calibrated hardening response is compatible with those provided in Ref. [20] though not identical (i.e., possibly due to differences in the material state). The main difference lies in the value of the yield stress, which is very sensitive to the initial state of the material. For other grades, the following range is observed $\sigma_{y}=800-1100 \mathrm{MPa} \%$ [39], which encompasses the results of Figure 14. Let us note that the use of a complex geometry allowed for the calibration

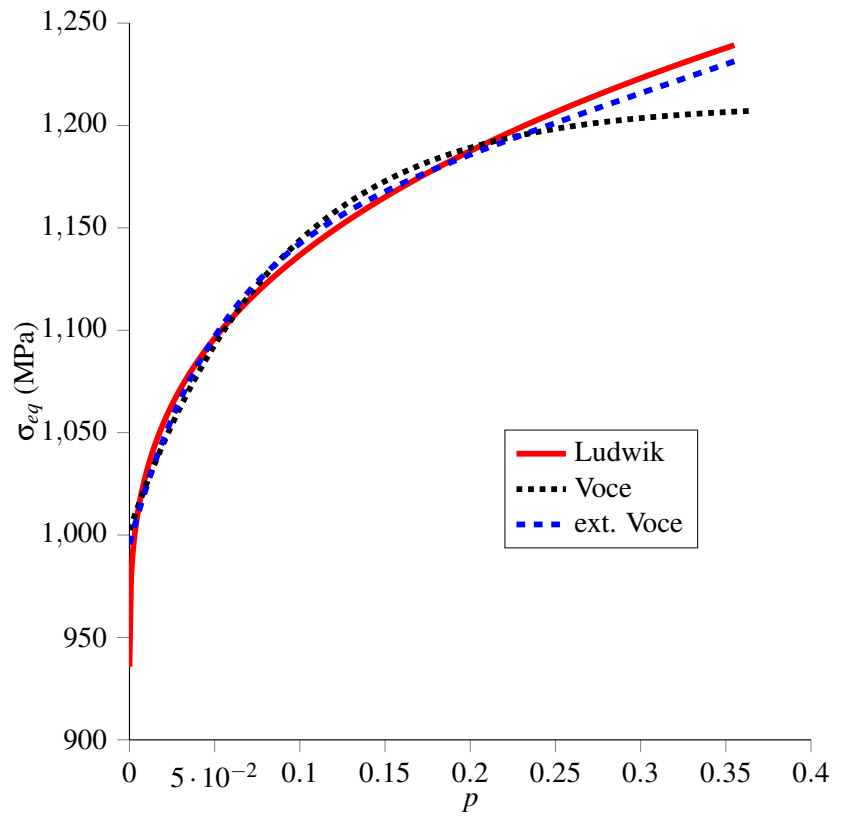

Fig. 14. True equivalent stress/plastic strain curves determined for the three chosen hardening postulates

of the hardening curve for much higher levels of equivalent plastic strain than observed in a tensile test (typically of the order of 0.10-0.16 [20,39]). Two curves are shown per analyzed test. The data of Ref. [20] correspond a tensile test on a smooth sample in the LD direction (solid symbols) and the extrapolated model used to predict via FE simulation the response of an experiment on a notched sample (solid line). For the present study, the result shown in Figure 14 for Voce's model (dashed line) is compared with that obtained for an identification up to the maximum load level $\left(F=F_{\max }\right)$ and subsequently extrapolated for higher strain levels (thin solid line). The extrapolation underestimates the actual material response by about $50 \mathrm{MPa}$.

In the following discussion, the results with Ludwik's law are considered for the 3D model with the finest mesh. This case has led to the smallest identification residual (Table 1) for the chosen constitutive equation.

\section{Discussion}

Having coupled measurement and simulation in a seamless (i.e., integrated) way, it is possible to discuss mechanical fields that cannot be directly assessed if full-field measurements were performed independently from simulations. Since 3D simulations are used to evaluate the sensitivities in the I-DIC procedure, it is possible to visualize various fields on the monitored surface but also within the bulk. In the following discussions, the midsection plane (i.e., parallel to the observed surface at a distance equal to half the sample thickness) is also considered.

Figure 16 shows von Mises' equivalent stress field $\sigma_{e q}(\mathbf{x}, t)$ on the midsection plane for two steps of the loading history. In elasticity, stress concentrations around the notch are observed. When plasticity has fully developed, the stress 


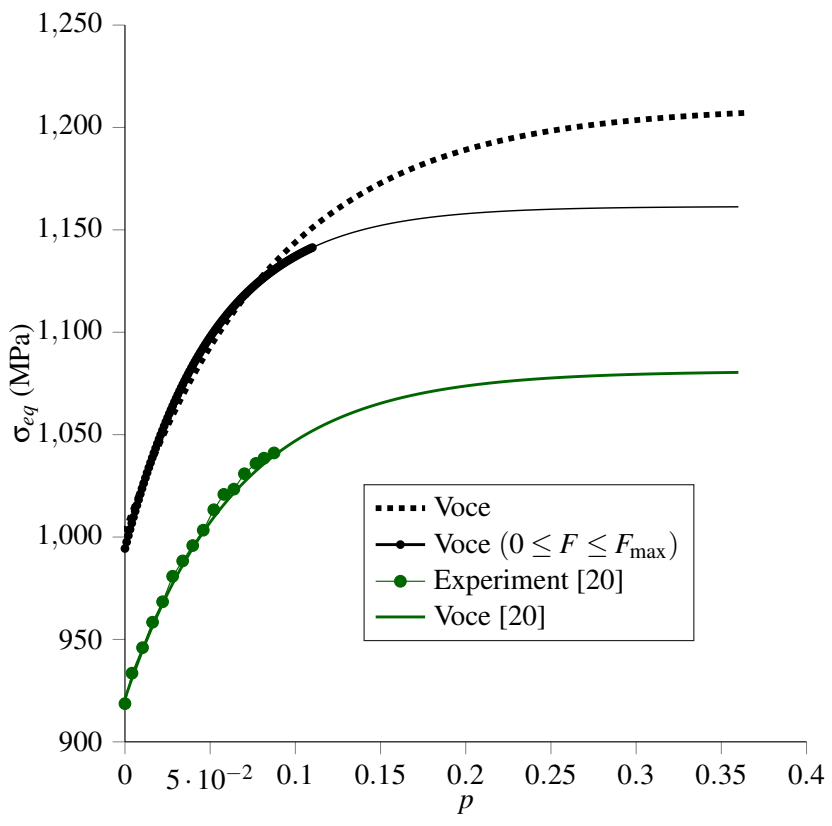

Fig. 15. Comparison of the calibrated hardening curve with the results of Ref. [20] (thin solid line: extrapolated values). For the present work, the dashed line corresponds to Voce's model shown in Figure 14 , the solid line to a calibration up to the maximum load level $\left(F_{\max }\right)$ and subsequently extrapolated

concentration has been significantly decreased.

Figure 17 shows von Mises' equivalent plastic strain field $p(\mathbf{x}, t)$ on the analyzed surface and in the midsection plane. Even though the overall levels are close, there is a clear difference between the two fields. In particular, the field in the midsection plane is more localized than on the external surface and the maximum level is higher (0.37 vs. 0.29). The fact that the mechanical fields are not identical on the external surface of the sample when compared with the midsection is a further confirmation that 3D simulations are needed, even though they are coupled with 2D surface measurements.

The triaxiality $\eta(\mathbf{x}, t)=\sigma_{h}(\mathbf{x}, t) / \sigma_{e q}(\mathbf{x}, t)$ is another field that can be extracted from the FE simulations (Figure 18), where $\sigma_{h}$ denotes the hydrostatic stress. In the elastic regime, the field is very similar in terms of distribution in the midsection plane and on the external surface. The maximum levels are very close.

Conversely, when yielding occurs, the triaxiality field is more localized in the midsection plane than on the external surface (Figure 19). Further, the maximum levels are no longer similar (i.e., 0.7 vs. 0.59). These overall trends are similar to those observed for the cumulated plastic strain fields shown in Figure 17 for the same loading step.

Last, the stress triaxiality is shown in Figure 20 for four different points as a function of the corresponding cumulated plastic strain. Two of the considered points are located on the notch tip and the other two in the center of the two analyzed sections. For the two points close to the notch tip, the stress triaxiality remains virtually constant because of the
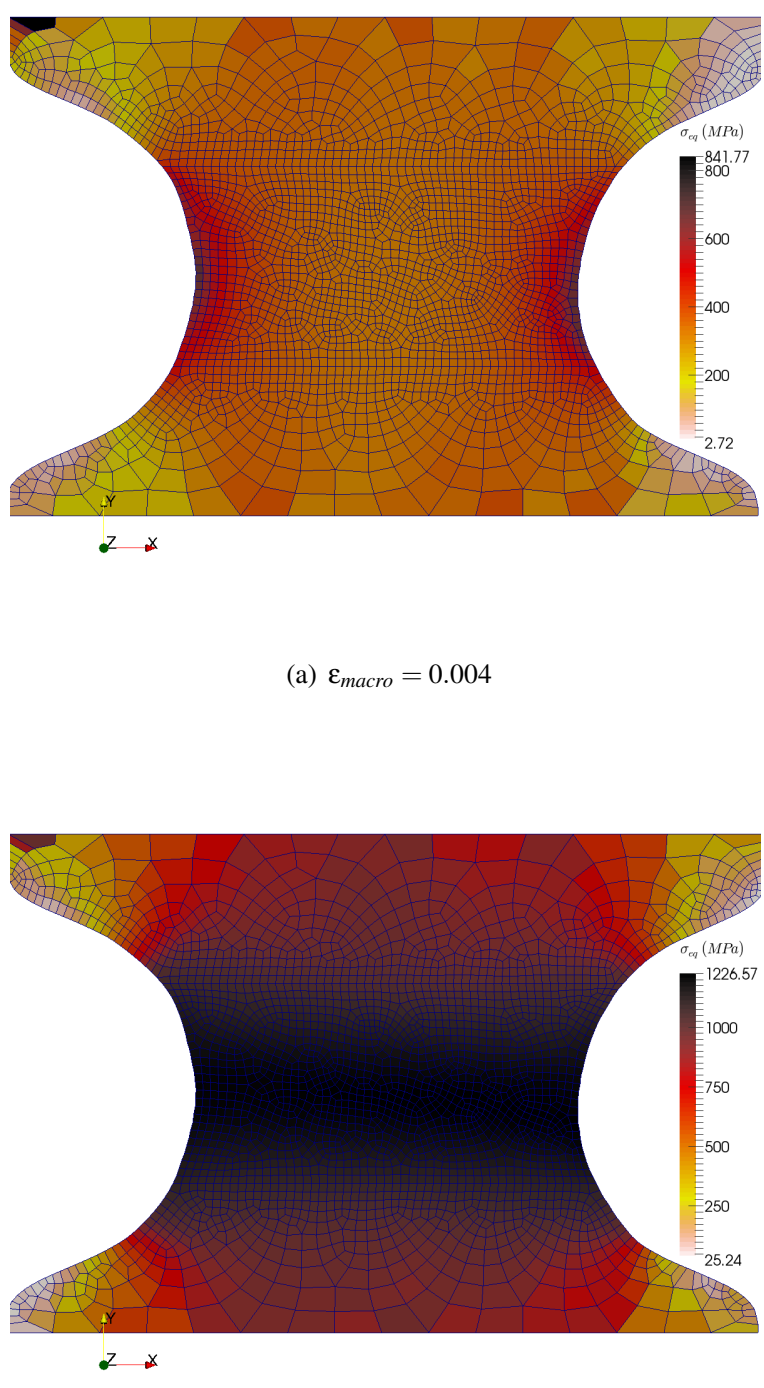

(b) $\varepsilon_{\text {macro }}=0.072$

Fig. 16. Von Mises' equivalent stress maps in the elastic regime (a) and fully developed elastoplastic step (b)

free-edge condition. Conversely, the two central points experience significant fluctuations of stress triaxiality during the test. The point located in the midsection plane reaches the highest level (i.e., 0.63) at the end of the experiment. A 2D simulation would not have been able to capture such high level.

Table 1 gathers the triaxiality levels for the different models investigated herein. In elasticity, $\eta_{\max }=0.49$ for the middle points on the surface and in the midsection plane. A 2D computation leads to similar levels. Conversely, in plasticity there is a significant difference between the triaxiality levels observed at the end of the test with 2D simulations (i.e., $\eta_{\max }=0.57$ ) and 3D results (i.e., $\eta_{\max }=0.7$ ). This result further underlines the differences between $2 \mathrm{D}$ and $3 \mathrm{D}$ 
simulations in the present analysis. The hardening law is of secondary importance and the fact that the global identification level was similar led also to very close estimates of $\eta_{\max }$. Last, in terms of maximum equivalent plastic strain, the results with I-DIC-3D-f are very close for the three hardening postulates (i.e., $p_{\max } \approx 0.36$ ). When compared with I-DIC-2D, there is clear difference.

\section{Conclusions}

It has been shown that triaxiality fields can be estimated in a thin notched sample made of Ti 6-4 alloy via integrated DIC. This type of approach seamlessly combines image registration and finite element simulations. It is worth noting

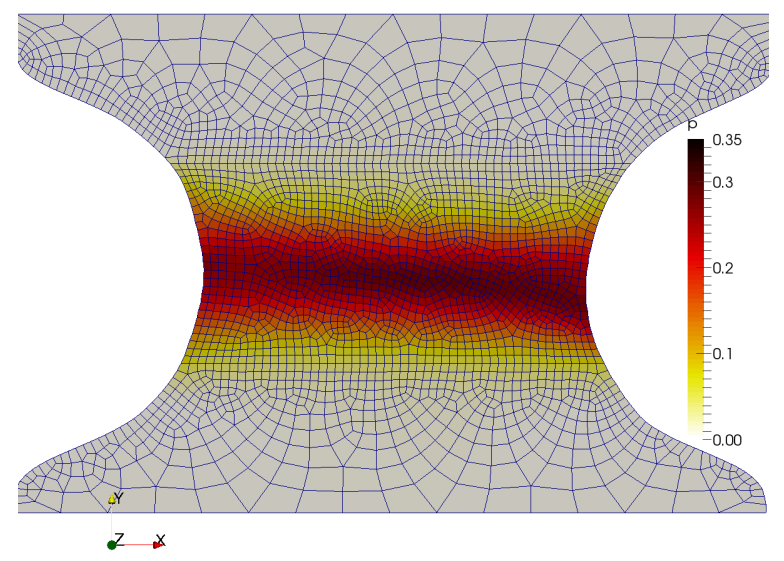

(a) External surface

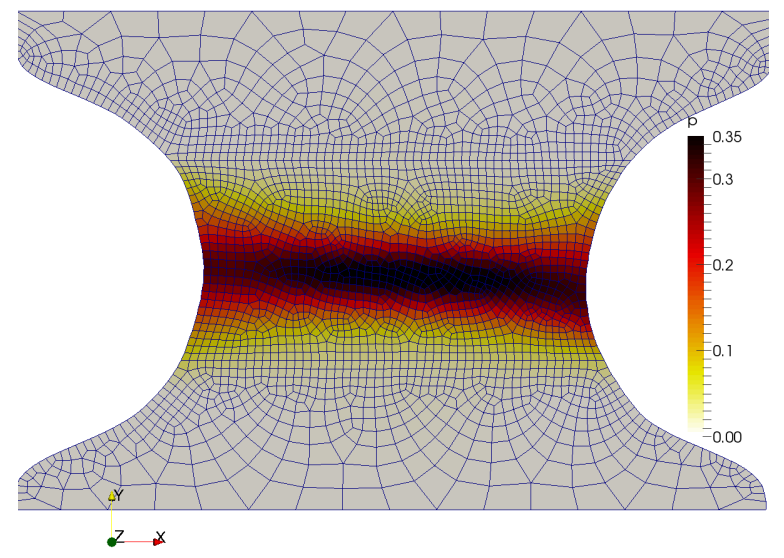

(b) Midsection plane

Fig. 17. Von Mises' equivalent plastic strain maps for two different locations when $\varepsilon_{\text {macro }}=0.072$

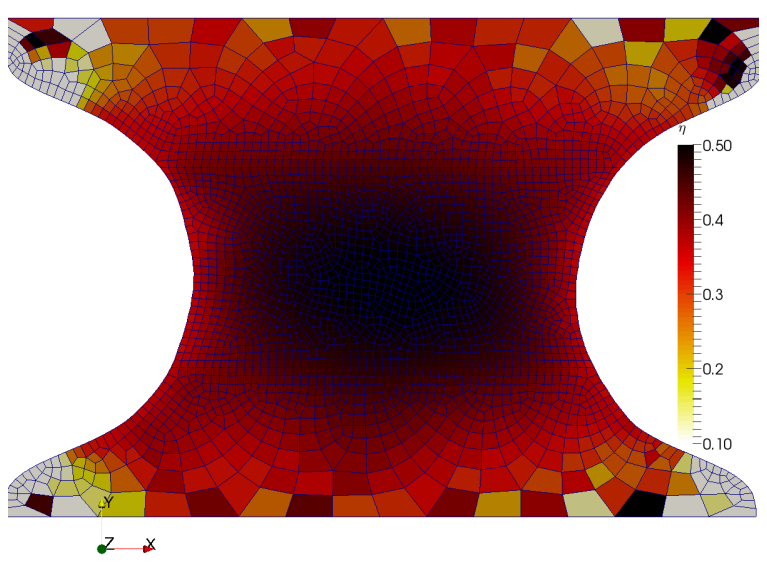

(a) External surface

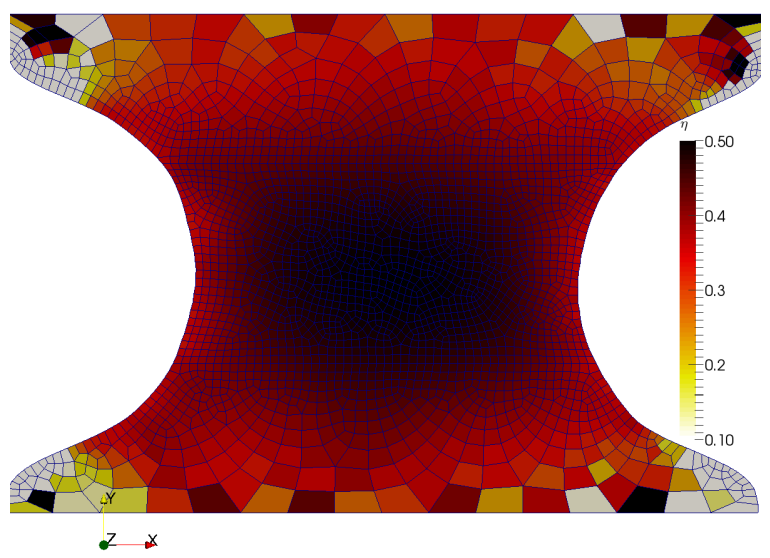

(b) Midsection plane

Fig. 18. Triaxiality maps for two different locations when $\varepsilon_{\text {macro }}=$ 0.004 (i.e., elastic regime)

that each sample can be analyzed independently and no a priori information on the material parameters is needed. One of the additional outputs of such an approach thus is the material parameters of the chosen constitutive model, which are needed to estimate stresses, and the identification quality based on gray level residuals and global equilibrium gap.

In the studied experiment it was shown that 3D simulations are needed to lower the correlation residuals and that fine meshes are desirable to get more trustworthy results. These meshes are unaccessible with standard DIC procedures for which the finer the element size the larger the measurement uncertainties [30]. If the discretization becomes too fine, the registration cannot be performed. To the authors' best of knowledge, it is the first time that I-DIC 
results are reported for discretizations that are significantly finer than achievable with standard global DIC approaches in elastoplastic cases. Further, C8 element have been used to properly recover a correct state of pressure around the ligament, a region which is in a nearly incompressible state. With I-DIC, the number of unknowns becomes very small (i.e., the material parameters), thereby providing a strong robustness. In the present case, the poor texture and paint cracking made standard DIC analyses very challenging if not impossible.

For the notched sample analyzed herein, the maximum strain levels were at least three times higher than the macroscopic strains to failure evaluated on smooth samples. Thus, the constitutive laws were probed in a significantly larger

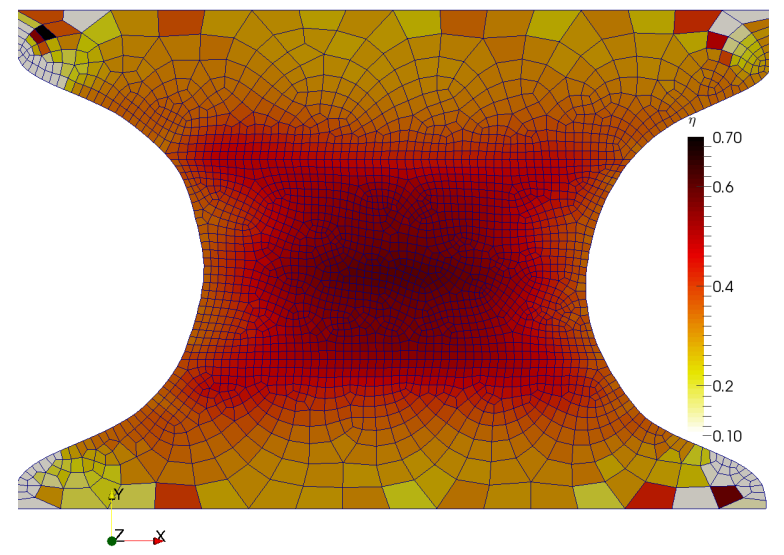

(a) External surface

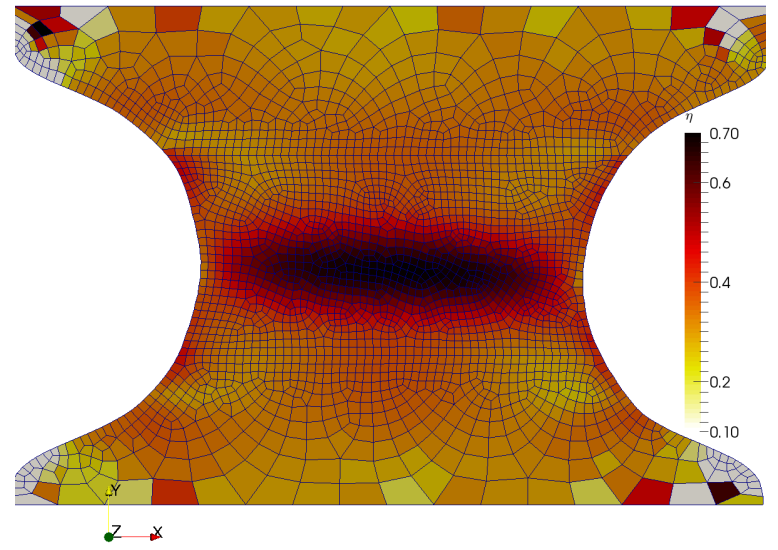

(b) Midsection plane

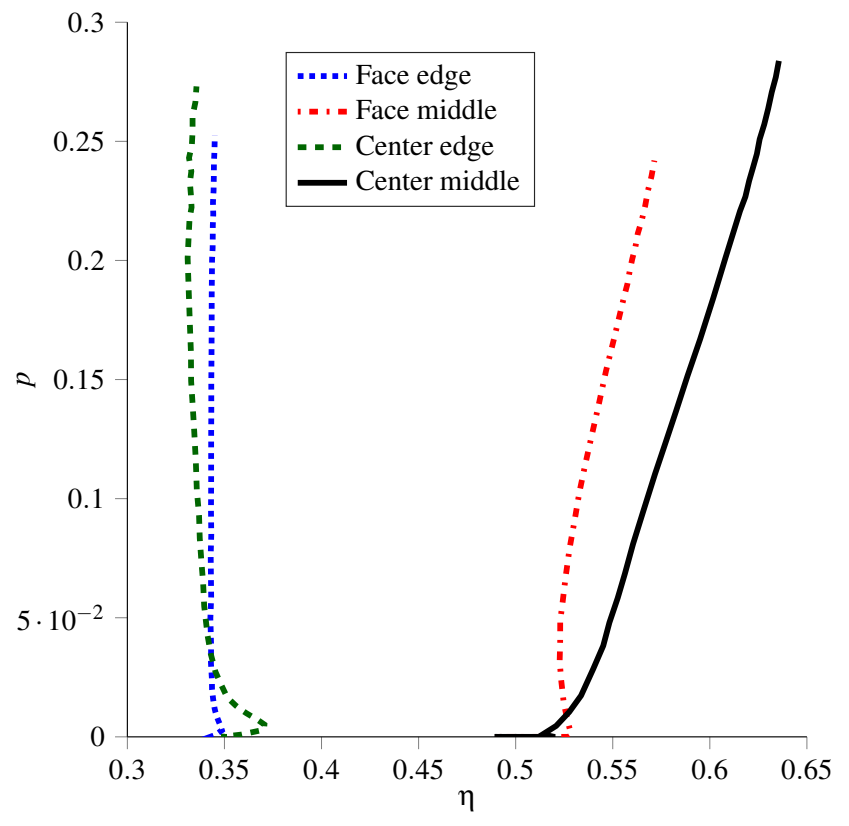

Fig. 20. Triaxiality history for four different points either located at the notch tip or in the center of the considered surfaces (i.e., external plane or midsection plane)

strain range. In terms of identification levels, the three investigated isotropic hardening laws led to similar global identification residuals. The detail of the chosen model seems secondary except for elasticity that led to very large errors. However, beyond the ultimate load level, significant errors detected on the gray level residuals indicate model errors associated with strain localization. Conversely, the load residuals remained of the same order of magnitude as in the first part of the experiment.

It is shown that the estimation of triaxiality fields requires 3D simulations even when the considered samples are thin. This is especially true when elastoplasticity is fully developed. The maximum levels of triaxiality are reached in the bulk of the sample (i.e., What is essential is invisible to the ey $e^{1}$ ). In the present case, the maximum triaxiality is virtually independent of the details of the isotropic hardening law. However, it is significantly different from the levels observed in elasticity or even with $2 \mathrm{D}$ plane stress simulations.

The next step of such analyses is to enrich the constitutive law to lower the identification residuals. In Ref. [20] anisotropy of the plastic response was observed and modeled. Similarly, twinning may occur. The I-DIC procedure developed herein can be extended to anisotropic yield surfaces and more complex hardening models. A damage model may also be coupled with the hardening law. In such constitutive models, the role of stress triaxiality is known to be of primary importance $[6,15-18]$.

Last, only one external surface was observed and the measured (Dirichlet) boundary conditions were extruded for 3D simulations. This hypothesis may induce errors that can

\footnotetext{
${ }^{1}$ Antoine de Saint-Exupéry (1943) "The Little Prince" Reynal \& Hitchcock (USA)
} 
be lowered by using at least another camera (for the opposite surface) or by applying a regularization technique on the boundary conditions $[44,45]$. If the sample thickness increases, four instead of two cameras may be utilized. Stereocorrelation may also be considered to evaluate $3 \mathrm{D}$ surface displacements. Another route is also possible by resorting to computed tomography [46] or laminography [47] in which digital volume correlation is a useful tool to reveal strain localization induced by plasticity [48]. All these experimental improvements may add more information that is useful when, say, integrated approaches are to be implemented.

\section{Acknowledgements}

The experiment reported herein was performed with the help of Xavier Pinelli. The I-DIC code used herein is part of the Metil platform developed by Hugo Leclerc [49]. This work has been funded by Turbomeca (SAFRAN Group). It is also a pleasure to acknowledge the support of Région Ile de France ("DICCIT" project).

\section{References}

[1] Robinson, E., 1944. "Bursting tests of steam-turbine disk wheels". Trans. ASME, 66, pp. 373-386.

[2] Mazière, M., Besson, J., Forest, S., Tanguy, B., Chalons, H., and Vogel, F., 2009. "Overspeed burst of elastoviscoplastic rotating disks - Part I: Analytical and numerical stability analyses". Eur. J. Mechanics A/Solids, 28(1), pp. 36-44.

[3] Mazière, M., Besson, J., Forest, S., Tanguy, B., Chalons, H., and Vogel, F., 2009. "Overspeed burst of elastoviscoplastic rotating disks - Part II: Burst of a superalloy turbine disk". Eur. J. Mechanics - A/Solids, 28(3), pp. 428-432.

[4] Hosford, W., 1972. "A generalized isotropic yield criterion". J. Appl. Mech., 39, pp. 607-609.

[5] McClintock, F., 1968. "A criterion for ductile fracture by growth of holes". J. Appl. Mech., 35(2), pp. 363371.

[6] Rice, J., and Tracey, D., 1969. "On the ductile enlargement of voids in triaxial stress fields". J. Mech. Phys. Solids, 17, pp. 201-217.

[7] Lode, W., 1925. "The influence of the intermediate principal stress on yielding and failure of iron, copper and nickel". Zeits. Angew. Math. Mech., 5, pp. 142149.

[8] Zhang, K., Bai, J., and François, D., 2001. "Numerical analysis of the influence of the lode parameter on void growth". Int. J. Solids Struct., 38(32-33), pp. 5847 5856.

[9] Bao, Y., and Wierzbicki, T., 2004. "On fracture locus in the equivalent strain and stress triaxiality space". Int. J. Mech. Sci, 46(1), pp. 81-98.

[10] Barsoum, I., and Faleskog, J., 2007. "Rupture mechanisms in combined tension and shearmicromechanics". Int. J. Solids Struct., 44(17), pp. 5481-5498
[11] Nahshon, K., and Hutchinson, J., 2008. "Modification of the gurson model for shear failure". Eur. J. Mech. A/Solids, 27, pp. 1-17.

[12] Dunand, M., and Mohr, D., 2011. "On the predictive capabilities of the shear modified gurson and the modified mohr coulomb fracture models over a wide range of stress triaxialities and lode angles". J. Mech. Phys. Solids, 59(7), pp. 1374-1394.

[13] Gao, X., Zhang, T., Zhou, J., Graham, S., Hayden, M., and Roe, C., 2011. "On stress-state dependent plasticity modeling: Significance of the hydrostatic stress, the third invariant of stress deviator and the non-associated flow rule". Int. J. Plasticity, 27(2), pp. 217-231.

[14] Malcher, L., Andrade Pires, F., and César de Sá, J., 2012. "An assessment of isotropic constitutive models for ductile fracture under high and low stress triaxiality”. Int. J. Plast., 30-31, pp. 81-115.

[15] Gurson, A., 1977. "Continuum theory of ductile rupture by void nucleation and growth: Part i - yield criterion and flow rules for porous ductile media". ASME J. Eng. Mat. Techn., 99, pp. 2-15.

[16] Lemaitre, J., 1984. "How to use damage mechanics". Nucl. Eng. Design, 80, pp. 233-245.

[17] Needleman, A., and Tvergaard, V., 1984. "An analysis of ductile rupture in notched bars". J. Mech. Phys. Solids, 32(6), pp. 461-490.

[18] Tvergaard, V., and Needleman, A., 1984. "Analysis of the cup-cone fracture in a round tensile bar". Acta Metall., 32(1), pp. 157-169.

[19] Koplik, J., and Needleman, A., 1988. "Void growth and coalescence in porous plastic solids". Int. J. Solids Struct., 24(8), pp. 835-853.

[20] Tuninetti, V., Gilles, G., Milis, O., Pardoen, T., and Habraken, A., 2015. "Anisotropy and tensioncompression asymmetry modeling of the room temperature plastic response of ti-6al-4v". Int. J. Plasticity, 67, pp. 53-68.

[21] Wattrisse, B., Chrysochoos, A., Muracciole, J., and Némoz-Gaillard, M., 2001. "Analysis of strain localisation during tensile test by digital image correlation". Exp. Mech., 41(1), pp. 29-39.

[22] Besnard, G., Hild, F., and Roux, S., 2006. ““'finiteelement" displacement fields analysis from digital images: Application to portevin-le châtelier bands". Exp. Mech., 46, pp. 789-803.

[23] Rastogi, P., ed., 2000. Photomechanics, Vol. 77 of Topics in Applied Physics. Springer, Berlin (Germany).

[24] Rastogi, P., and Hack, E., eds., 2012. Optical Methods for Solid Mechanics. A Full-Field Approach. Wiley$\mathrm{VCH}$, Berlin

[25] Hild, F., and Roux, S., 2012. Digital Image Correlation. Wiley-VCH, Weinheim (Germany), pp. 183-228.

[26] Sutton, M., 2013. "Computer vision-based, noncontacting deformation measurements in mechanics: A generational transformation". Appl. Mech. Rev., 65(AMR-13-1009, 050802).

[27] Sutton, M., Orteu, J., and Schreier, H., 2009. Image correlation for shape, motion and deformation mea- 
surements: Basic Concepts, Theory and Applications. Springer, New York, NY (USA).

[28] Broggiato, G., 2004. "Adaptive image correlation technique for full-field strain measurement". In 12th Int. Conf. Exp. Mech., C. Pappalettere, ed., McGraw Hill, Lilan (Italy), pp. 420-421.

[29] Sun, Y., Pang, J., Wong, C., and Su, F., 2005. "Finiteelement formulation for a digital image correlation method". Appl. Optics, 44(34), pp. 7357-7363.

[30] Hild, F., and Roux, S., 2012. "Comparison of local and global approaches to digital image correlation". Exp. Mech., 52(9), pp. 1503-1519.

[31] Hild, F., and Roux, S., 2006. "Digital image correlation: From measurement to identification of elastic properties - a review". Strain, 42, pp. 69-80.

[32] Roux, S., and Hild, F., 2006. "Stress intensity factor measurements from digital image correlation: postprocessing and integrated approaches". Int. J. Fract., 140(1-4), pp. 141-157.

[33] Leclerc, H., Périé, J., Roux, S., and Hild, F., 2009. Integrated digital image correlation for the identification of mechanical properties, Vol. LNCS 5496. Springer, Berlin, pp. 161-171.

[34] Réthoré, J., 2010. "A fully integrated noise robust strategy for the identification of constitutive laws from digital images". Int. J. Num. Meth. Eng., 84(6), pp. 631660.

[35] Mathieu, F., Leclerc, H., Hild, F., and Roux, S., 2015. "Estimation of elastoplastic parameters via weighted FEMU and Integrated-DIC". Exp. Mech., 55(1), pp. 105-119.

[36] Kavanagh, K., and Clough, R., 1971. "Finite element applications in the characterization of elastic solids". Int. J. Solids Struct., 7, pp. 11-23.

[37] Grédiac, M., and Hild, F., eds., 2012. Full-Field Measurements and Identification in Solid Mechanics. ISTE / Wiley, London (UK).

[38] Ghahremaninezhad, A., and Ravi-Chandar, K., 2012. "Ductile failure behavior of polycrystalline al 6061-t6". Int. J. Fract., 174(2), pp. 177-202.

[39] Abouridouane, M., 2005. "Bruchverhalten von leichtmetallen unter impact-beanspruchung" (in German). Phd thesis.

[40] Cooreman, S., Lecompte, D., Sol, H., Vantomme, J., and Debruyne, D., 2007. "Elasto-plastic material parameter identification by inverse methods: Calculation of the sensitivity matrix". Int. J. Solids Struct., 44(13), pp. 4329-4341.

[41] Ludwik, P., 1909. Elemente der technologischen Mechanik. Verlag Von Julius Springer (Leipzig, Germany).

[42] Voce, E., 1948. "The relationship between stress and strain for homogeneous deformation". J. Inst. Met., 74, pp. 537-562.

[43] Zienkievicz, O., and Taylor, R., 1989. The Finite Element Method. 4th edition. McGraw-Hill, London (UK).

[44] Allix, O., Feissel, P., and Nguyen, H., 2005. "Identification strategy in the presence of corrupted measure- ments". Eng. Comput., 22(5-6), pp. 487-504.

[45] Feissel, P., and Allix, O., 2007. "Modified constitutive relation error identification strategy for transient dynamics with corrupted data: The elastic case". Comput. Meth. Appl. Mech. Eng., 196(13/16), pp. 1968-1983.

[46] Maire, E., and Withers, P. J., 2014. "Quantitative X-ray tomography”. Int. Mat. Rev., 59(1), pp. 1-43.

[47] Morgeneyer, T., Helfen, L., Sinclair, I., Proudhon, H., $\mathrm{Xu}, \mathrm{F}$, and Baumbach, T., 2011. "Ductile crack initiation and propagation assessed via in situ synchrotron radiation computed laminography". Scripta Mat., 65 , pp. 1010-1013.

[48] Morgeneyer, T., Taillandier-Thomas, T., Helfen, L., Baumbach, T., Sinclair, I., Roux, S., and Hild, F., 2014. "In situ 3d observation of early strain localisation during failure of thin al alloy (2198) sheet”. Acta Mat., 69, pp. 78-91.

[49] Leclerc, H., 2007. "Plateforme metil : optimisations et facilités liées à la génération de code". In 8e Colloque National en Calcul des Structures. 